- Penelope Brown

MAX PLANCK INSTITUTE OF PSYCHOLINGUISTICS, NITMEGEN, THE NETHERLANDS

\title{
Conversational Structure and Language Acquisition: The Role of Repetition in Tzeltal
}

When Tzeltal children in the Mayan community of Tenejapa, in southern Mexico, begin speaking, their production vocabulary consists predominantly of verb roots, in contrast to the dominance of nouns in the initial vocabulary of first-language learners of Indo-European languages. This article proposes that a particular Tzeltal conversational feature-known in the Mayanist literature as "dialogic repetition" - provides a context that facilitates the early analysis and use of verbs. Although Tzeltal babies are not treated by adults as genuine interlocutors worthy of sustained interaction, dialogic repetition in the speech the children are exposed to may have an important role in revealing to them the structural properties of the language, as well as in socializing the collaborative style of verbal interaction adults favor in this community.

L ooking at Tzeltal Mayan language learners, we find a puzzle. Tzeltal children begin speaking by uttering, for the most part, verb roots, which have been stripped of their affixes and appear initially alone (Brown 1997, 1998a). Since in this society there is very little verbal interaction with preverbal children, and since children rarely hear verb roots alone, how they achieve this seems puzzling, especially in the light of what we know about how children learning European languages begin the process.

In English and the other European languages intensively studied by developmental psycholinguists and others interested in child language, a consensus has arisen on the early "bootstraps" or things that help a child start

Joumal of Linguistic Anthropology 8(2):197-221. Copyright $\odot 2000$, American Anthropological Association. 
learning language (at the prelinguistic and one- to two-word stages). Actually, "consensus" may be too strong, but at least there is broad agreement about what helps the speed and ease of entry to language; there is agreement on this early stage although there is rabid disagreement on the relative importance of each of these factors, as well as on later stages. The first important element is intensive mother-child interaction, with "contingent responding." From frequent sessions of dyadically structured ritual interaction with openings and closings keyed by gaze, the child gets the idea that her behavior has a predictable effect on the world, and the idea of a "signal" (Snow 1981, 1984). Secondly, motherese is seen as important, if not essential; a special child-oriented style, simplified, prosodically marked, and attuned to what the child can understand, has an important role in presenting language information to the child highlighted and in a form she can use (Cruttenden 1994; Pine 1994; Snow and Ferguson 1977). ${ }^{1}$

There is also general agreement about the trajectory of the first stages of language learning (Clark 1993): the child starts with attention-garnering words (e.g., words meaning 'look', 'this', or 'there'), concrete nouns (e.g., 'doggie'), and a handful of non-nominal words ('more', 'allgone', 'up', 'no', 'again', etc.). The functions of these first words-words that do things like noticing, commenting on disappearance, on success/failure, refusing offers or commands, repeating what the prior speaker has said-are related to concepts the child is cognitively developing at this time (Gopnik 1981). Then, at around 18 months, there is a "naming explosion," with the child producing lots of new concrete nouns. For the first year or so of speaking, however, the child relies on a small handful of verbs.

A favored explanation proffered for the early prevalence of nouns over verbs is that concrete nouns are semantically simpler than verbs, and easier to link to their referents. Nouns label "natural categories" observable in the world, while verbs label more linguistically and culturally specific categories of events linking objects belonging to such natural categories (Clark 1993; Gentner 1978, 1982). Verbs are learned later than concrete nouns because they are semantically complex, having relational meanings; their semantics is also cross-linguistically more variable than nouns. They are also morphologically more complex (usually having more inflections than nouns). And the link between the linguistic form and the context is harder to establish, since actions and events don't come individuated the way concrete objects do (Gleitman 1990).

Depending on your theory, you might also hold that the language-learning child is helped by innate notions, for example by Universal Grammar, or by word learning constraints that restrict the hypotheses a child entertains as to word meanings (Markman 1994), or by Operating Principles (Slobin 1985), which are universally available heuristics like "Pay attention to the ends of words, and to perceptually salient stretches of speech."

In light of this general agreement about the first stages of language acquisition, children's acquisition of the Mayan language Tzeltal poses a puzzle, since (1) there is no intense mother-child verbal interaction with prelinguistic children; they are hardly talked to, and (2) there is minimal motherese; child-directed speech is not necessarily slower or phonologically 
simplified, and is very often whispered. ${ }^{2}$ Furthermore, the crucial meaning units-Tzeltal CVC verb roots-rarely occur alone, but are buried between phonological material in front and behind (obligatory prefixes and suffixes), and are prosodically masked (Brown 1997). Yet Tzeltal children when they start producing words start with deictic attention-getters, a few nouns (like Western children) and then lots of verbs (Brown 1998a). ${ }^{3}$ There is no evidence in early production of a prior "naming explosion"; verbs and nouns come into productive use together. This seems to be a Mayan-wide pattern. ${ }^{4}$

So the puzzle is this: Tzeltal children seem to solve a hard problem (verbs) very early, in the face of less helpful input!

I think that Tzeltal children solve this problem with the help of (at least) three kinds of information that is available in the language that is spoken around them, if not necessarily to them. First, there are structural facts about the nature of verb roots in this language: they have a predictable CVC shape that is (for the most part) inviolable, there are no consonant clusters in roots, and morphophonemic variations are relatively minimal. ${ }^{5}$ Tzeltal noun roots are more variable than verb roots, but the predictability of the CVC verb root shape should help the child to segment it from the speech stream. Second, there are distributional facts about the linguistic contexts where the verb root is exposed at the front or back; where, for example, null morphemes make the root utterance-initial or utterance-final. This, however, occurs in the input on the order of only 10 percent of the time (Brown 1997). These two kinds of information are used by children everywhere to get a handle on their language. But what I will argue here is that Tzeltal children have the advantage of a third kind of information, which, given the paucity of speech to young children, is crucial. This is information carried in interactional facts, and in particular in the characteristic conversational style of Tzeltal. Tzeltal conversational interaction is characterized by a large amount of "dialogic repetition," involving a particular addition to default turn-taking rules that has the property of highlighting new information (and therefore often verb roots) across adjacent turns at talk (Brown 1996).

In terms of Slobin's (1985) Operating Principles for how children extract information from the speech stream, I will argue that the Tzeltal children behave as if they are following an Operating Principle along the lines of: "Pay attention to what remains constant across repeated versions of an utterance, even if it is utterance-internal and prosodically unprominent." This is a somewhat unorthodox principle, in light of the child language literature. The present article examines dialogic repetition in Tzeltal to show how Tzeltal conversational structure can help the child to do this.

To preview my argument here: (1) A special kind of repetition is part of a culturally stabilized Tzeltal (and indeed, Mayan) style of conversational organization. (2) Tzeltal children of, say, two years old are already sensitive to this fact (there is evidence of it in their speech even at the one- and two-word stage). (3) This repetition has a potentially important role in the language- (and especially verb-) learning process. 


\section{The Context for Language Learning}

\section{The Ethnographic Context}

The Tzeltal speech community reported on here consists of Mayan peasant farmers in highland Chiapas, in the municipio of Tenejapa, a remote and traditional Mayan Indian community. These people are still mostly monolingual, and mostly illiterate. The impact of Spanish in the home is still minimal; all speech to small children is in Tzeltal, although rapid social change within the last five years means that this picture can be expected to change within the short-term future. The database for children's speech comes from a four-year longitudinal study of child first language acquisition in five families. ${ }^{6}$

\section{Child-Rearing Practices}

Tzeltal babies are always carried on someone's back, at first the mother's, then often another caregiver-a sibling, cousin, or grandmother. Children of six to eight, boys as well as girls, are common caregivers, a role they carry out (by and large) with great affection and responsibility. Babies are slept with, and nursed on demand. They are rarely out of physical contact with a caregiver until they are walking, around age 1;6. They are initially considered to be very vulnerable to sickness and soul loss, to be protected, not yet stimulated or interacted with, in line with the Mayan-wide cultural pattern. There is in fact little chance for babies to interact or to physically explore the world; they lie or sit (in a shawl on the caregiver's back, or on someone's lap facing outward, or propped up in a cardboard box), and observe what is happening around them. They are given things to distract them from fears or crying, and are rocked on the caregiver's back to calm them. But very little speech is addressed to them, mainly things like: Don't cry', 'Go to sleep', and the like, often whispered.'

\section{Language Input}

Speech addressed directly to Tzeltal babies is fairly minimal; they are talked to mostly by siblings (or doting grandparents). There is a very minimal baby talk register (involving high pitch, slowed-down speed, and a handful of special words) which, however, is by no means always employed when talking to babies. Because of the physical intimacy generated by constant caregiver-baby contact, there is nonverbal intimacy, including acute awareness of a baby's inadvertent cues to imminent crying, excreting, or vomiting. ${ }^{8}$ But verbal communication emerges very gradually. During the first six months of a baby's life there is almost no verbalization at all addressed to her.' During the second six months, caregivers and the baby occasionally coattend: for example, the adult with the baby seated on her lap will turn a baby's face outward and "make it talk" to others. There may also be elicitation routines even though the baby can't talk at all yet (as reported also by de León, this volume, for Tzotzil). Tzeltal caregivers, like their Tzotzil counterparts, do treat the baby as a 'proto-speaker' (de León, 
this volume) by attributing communicative "ideas" to her (e.g., telling other children what the baby wants, using quotative particles to report what the baby "says"). This is not serious evidence of interlocutorhood, however, since adults do this with animals too.

Toward the end of the first year caregivers begin to attend more systematically to the baby's attention-drawing gestures and vocalizations. The child still does not get much speech addressed directly to her (perhaps a total of 30 utterances per day)..$^{10}$ During the third six months (or until the child is walking) for perhaps a maximum of one-half hour per day in total a child is interacted with; otherwise she is a bystander, sitting up in her carry-shawl and watching the events and interactions around her.

Between the ages of about $1 ; 6$ to 2,0 by far the majority of utterances addressed to a Tzeltal child are imperatives, warnings and imprecations aimed at controlling the child's behavior. There may be some elicititation routines (e.g., the names for body parts), there is occasional engagement in drawing the child out, and increasing attention to the child's own communicative initiatives. But small children are relatively passive and often late starters in producing language, many hardly talking (just a handful of onemorpheme utterances and pointings or attention-getting grunts) until age 2;0. Small children are not at first expected to obey commands; these are routinely given but, if ignored by the child, are not enforced, and noncompliance is not punished. This immunity lasts till around age 3,0. From about the time when the child begins to speak in two-word utterances we find sustained verbal interaction over more than one turn, from roughly age two on. From then on the child's acquisition of her language, though perhaps slightly delayed in production vocabulary, is not out of line with that of Western children.

To summarize: small Tzeltal children are not normally the focus of adult interactional attention; when they are it is mostly an attempt to control their behavior and movements - to prevent injury, keep them close at hand, attend to their needs, and so forth. Adults interact with each other over babies, but the babies are not on the whole treated as interlocutors. What this means is that small children's access to adult language is to a very large degree passive, although if they are not the only child in their household they do interact more with other children, who are often only a bit more linguistically advanced. Given this picture of Tzeltal child rearing, what role might Mayan dialogic repetition have to play in these children's language acquisition?

\section{Repetition in Discourse}

It has long been recognized that parallelism of various sorts (different kinds of repetition) is a highly productive stylistic resource in Mayan languages (Fought 1985; Hanks 1989; Hofling 1993; Norman 1980; Tedlock 1983). More recently, it has been recognized what a pervasive role such parallelism plays in everyday narrative contexts and in conversational exchanges (Brody 1986, 1994, 1996; Brown 1979, 1990; Hofling 1996; Martin 1994, in press; Stolz 1996). "Such "dialogic repetition" functions to manage 
the flow of discourse, regulate the introduction of new information and the development of topics, seek or emphasize agreement, create discourse boundaries, and collaboratively construct discourse understanding.

The presence of dialogic repetition as a highly frequent property of everyday Mayan adult conversations is of interest to investigations of child language learning in such languages, since repetition is also an important resource in early child language. Three kinds of repetition in adult-child interactions have been reported in many languages to be a part of "motherese" style, frequent in speech to small children. ${ }^{12}$ The first is self-repetitions: a matter of repeating or rephrasing one's utterance on repeated tries, trying to get the child's attention or understanding - what Küntay and Slobin (1996) have called variation sets in input to young Turkish children. Underlying a variation set is a single communicative intention, which is rephrased and repeated with lexical substitutions, addition and deletion of specific reference, and reordering. ${ }^{13}$ Although this is self-repetition, it is interactive in being adapted to the child's perceived response (or lack thereof). In Turkish, because of the broad range of morphological variation and extensive possibilities for ellipsis and reordering, the Turkish language-learner routinely receives "complexly-textured variation sets," which, Küntay and Slobin argue, are an important factor in Turkish children's early acquisition of verbs. I want to make an analogous argument for the particular kind of repetition we find in Tzeltal.

A second kind of repetition in language to small children has been called expansions (Brown and Bellugi 1964), where the adult reformulates the child's prior utterance to express the presumed communicative intent in a grammatically correct way (and often to make a communication check). Expansions repeat the child's attempted utterance production with corrected pronunciation and filled-in missing morphemes. Given the indeterminacy of the child's communicative intent, this kind of repetition has been called parental "glossing" (Scollon 1982), and even "guessing" (Ochs 1984, 1991; Ochs and Schieffelin 1995).

A third type is found in prompting routines, or the elicited repetition scenario reported for many different cultures. In response to a caregiver saying: 'say such and such', the child says: 'such and such', as in Schieffelin's (1990) well-known example from the Kaluli of New Guinea. Elicited imitation of this sort-involving explicit socialization of how to talk to others-pervades caregiver-child interactions in some societies (see Demuth 1986; Eisenberg 1986; Ochs 1988; Schieffelin 1990; Watson-Gegeo and Gegeo 1986). This too is prevalent in Tzeltal caregiver speech to children once they are beyond the one- or two-word stage.

All three of these-variation sets, expansions, and prompting routinesare appropriate to a less competent interlocutor (they are used in motherese, and foreigner talk); they would be inappropriate between adults in other contexts. Tzeltal speech to small children, relatively infrequent though it may be, has all of these well-attested forms of repetition. But Tzeltal conversation not addressed to small children also has yet another type, usually called by Mayanists dialogic repetition, characteristic of Tzeltal adult speech as well as child-directed speech. This is a special kind of repetition, with 
the following properties: (1) It is repetition across turns in conversation, (not, for example, recycling one's own turn in an attempt to get the floor, or make oneself clear, or other cases of repeating oneself in the construction of one's own turn); (2) the repetitions involve close formal parallelism (both semantic and syntactic) across two turns.

So by "dialogic repetition" I mean something quite precise: repetition of all or a significant portion of the same proposition that was provided in the immediately prior turn. The proposition must be in the same words, with the syntactic frame held constant, with appropriate deictic and evidential switches if necessary to keep the proposition the same. However, the prosody of the repeat is not necessarily the same; it may well vary, disambiguating various functions of the repeat, and connectives and sentential modifiers may also vary. Thus I am considering a formal parallelism in language, with a highly constrained prototype, leaving aside (for the moment) other forms of parallelism and paraphrase. This pattern of dialogic repetition is consonant with Tannen's analysis of "exact other" repetitions of an utterance in English (1987a:588)-person is varied if necessary, but no information is added, and no contribution (beyond affective reaction) is made to the development of the story or theme.

Unlike expansions that elaborate and fill in a less-than-fully-competent interlocutor's underspecified turn at talk, these dialogic repetitions actually truncate and run down, in the sense that they diminish across turns. Example (1) will illustrate the phenomenon. (Underlining identifies repetition of [part of] previous utterance, double underlining marks the original proposition that gets repeated, boldface marks shifts in deixis): ${ }^{14}$

(1) [ $k$ having arrived to visit $m$, her grandmother, is explaining how she decided to visit]

1. k; ya xba kil xon tal - ja' ye tz'i me(n) xk'otok tojle tal sab hav men ala bok ine

2. $m$; tz'imen alabok ine.

3. k; xk'otok to jle tal.

4. $\mathrm{m}$; ajj

5. k; ja' te ja'ye tz'in, la ka'yix tal ja'al jo'otike.

6. $\mathrm{m}$; ej!la'wa'yixtaltz'in.

7. k; la!

8. $m$; la. $\mathrm{a}^{\prime}$ in sabi.

9. $\mathrm{k}$; ja'

10. $\mathrm{m} ; \mathrm{ja}$

11. $k$; '
I'll go see them I said - $\underline{I}^{\prime}$ d just come back from fetching those greens just this morning.' [referring to greens from her garden, just given to $m$ as a gift ]

'These greens here.' [the gift]

' $I$ 'd come back from fetching them.' [repeats her own utterance]

'Ah.'

'So that's how it was, we got rained on on the way here.' [i.e., because she came in the afternoon, after fetching greens from her garden] 'Eh! So yougot it (i.e.w rained on) on the way here.'

'(We) did.'

'(You) did. It was this moming.' 'Itwas.'

'Itwas.'

'Itwas.' 
12. $\mathrm{m}$; ja' te (.) jich suit-at nix tal

'So it was you just returned then.'

13. $\mathrm{k}$; $\underline{\text { a tz'in. }}$ suitnixtzin.

14. $\mathrm{m}$; suit.

15. $\mathrm{k}$; sujt. 'Just returned then.'
'Returned.'
'Returned.'

This example illustrates various properties of dialogic repetition:

- Repetition is the canonical way to reply to a prior utterance offering new information or raising a new topic. It is a kind of socially necessary back-channel, although unlike, for example, back-channel "uhuh" in English, (1) it cannot overlap the prior speaker's turn but must occupy a turn of its own, and (2) it has the potential to convey much more than simply the "I hear you, go on" message of classic backchannel.

- It occurs with shifts of deixis and evidentiality (see 11. 1-2, the shift from 'these' to 'those'; 1l. 5-6, the shift from 'we' to 'you').

- Any word can be repeated alone (except for sentential particles and adverbs, and most aspect particles), even the completive particle la (11. 7 and 8), which except as a repeat cannot occur alone. So what counts as a word in Tzeltal is revealed in repeats, including some of what must be stripped to find the root (e.g., the particle la). ${ }^{15}$

This information is of course crucially important for the child, since segmenting an utterance into words and isolating their roots is a prerequisite to building up a mental lexicon of sound-meaning correspondences.

- The choice of which part of the prior utterance to repeat is most often the predicate, or what is newsworthy in the utterance, so verbs are favored to be highlighted by this process (as in 11. 6, and 13-15). Also favored are particles that stand for the whole proposition, like completive la, which, standing alone, means '(It) did (happen thus)' (as in 11. 7-8), or $j a$ ', a particle which when preposed to a clause means 'It is the case (that). ...' (as in 11. 9-11).

- Repetition diminishes or truncates across turns, each repeat in the cycle repeating a smaller and smaller portion, and the cycle may end with a nonrepeating ' $\mathrm{hm}$ '. This truncation can even include omission of person-marking suffixes (as in 11. 13-15, where sujt-at 'you returned' is repeated as sujt 'returned', rather than as sujt-on 'I returned'); such omission of person-markers is only grammatical in repeats. The crucial point here is that there is successive revealing of the structure of the sentence through these repeats, including and up to uttering just the bare root.

- Repetition can occur alone, the repeater thus handing the floor back to the interlocutor (as in 11. 2, 6-7, 9-11, and 13-15). Or it can be followed by a nonrepeated utterance, thereby initiating another cycle of repeats (as in 1.8 where the initial repeat la affirms the prior utterance, then the same speaker goes on to add a comment, $j a^{\prime}$ in sab $i$ 'it was this morning' that generates its own cycle of repeats (11. 9-11). 
Dialogic repeats of this kind can do many things, one of the most important of which is to turn an utterance into shared knowledge, as Keenan (1977) has argued for children's repeats in English conversations. Keenan's analysis is equally appropriate for Tzeltal: An addressee who repeats (or "expands") an utterance shows knowledge of that utterance; then both can treat it as given/old information. Often the repeated piece becomes the topic that then is commented upon, after being accepted (by being repeated). Once the receipt of a new piece of information has been acknowledged by repeating it, it is then doubly easy to build on later in the conversation. Therefore repeating can be a way of taking up and continuing a topic, or of affectively commenting on it by means of marked prosody, and thus a way of generating talk. Or it can be a way of winding down a topic (a bit like English "well's" and "ah hahs" on the telephone); you can get up to at least eight cycles of repeats devoted to saving, in effect: "Oh yeah, that's so." While the proposition is maintained across turns, there are intonational variants: the person who knows most about the proposition in question can express affirmation and reaffirmation of the truth of the proposition, along with nuances of attitude and affect; the respondant, or the one not controlling the knowledge about the proposition, can express nuances of surprise, interest, and so forth in the proposition and stress agreement with attitudes expressed by the other.

Three points about Tzeltal dialogic repetition must be stressed. First, however prominent, this repetition is not a blanket rule for back-channel. It depends on the nature of the communicative acts being performed. For example, it is not the appropriate way to respond to directive actscommands, threats, or warnings, (which predominate in adult speech to small children). And one can use a more minimal form $\left(\mathrm{mm}, \mathrm{jo} \mathrm{o}^{\prime}\right)$, although if you are an adult and this is all you do, without repeating, it conveys noninvolvement. Second, dialogic repetition is locally managed. In Schegloff's terms (1981:89) such stable recurrent forms of talk are "an orderliness wrested by the participants from interactional contingency, rather than [as] automatic products of standardized plans." Tha interactional contingency in the Tzeltal case is the presumption that a response to new information will affirm it, before developing the theme. Failure to do so is the basis for inferences (e.g., that you are angry, impatient, or urinterested). Elsewhere I have suggested (Brown 1996) that this presumption amounts to a modification of the Sacks et al. (SSJ) (1974) default turn-taking rules. The SSJ rules allow a speaker to self-select at a transition relevance point and continue speaking, whereas in Tzeltal the default assumption in extended conversation is that $C$ (Current Speaker) may not self-select without $\mathbf{N}$ (Next Speaker) having made some verbal response, which is usually a repeat of all or a salient part of the prior turn. ${ }^{16}$ The local management of this system is an important property if the young child is to take advantage of the information provided by it, and to learn to do it herself at an early age. The child does not need to understand the larger conversational patterns of topic continuity and maintenance in order to do this kind of turnby-turn decision-making about when to repeat. ${ }^{17}$ 
The third point to stress is that this convention of repeating is not just a feature of polite visiting conversations or gossip sessions, although it thrives there, instead it characterizes at least parts of all extended conversational exchanges. Example (1) above is polite style between adults, a style necessary in conversation with visitors or anyone who does not live in your own household. But many contexts even in very casual interaction demand repetition: for example, affirmative answers to yes/no questions, and confirmation of suppositions, affirmations, or assessments. In casual speech these are likely to be short, often two-turn sequences, while in polite speech they may be drawn out over several turns.

Thus, even though in very casual speech there are not normally drawnout repeat sequences extending over many turns, for the purposes of getting the structural information a two-turn repetition is all the child needs. This two-turn repetition occurs in virtually all the contexts in which small children hear adult speech to each other (at home, on the trails, working in the fields, visiting, riding on the bus to town). In the exceptions-public events where there are alternative speech exchange systems in play, such as church sermons, political speeches, community meetings, court cases, and religious rituals-small children are rarely attending to the speech. ${ }^{18}$

This convention has several important functions. It has a specific turnmanagement function: if you want to hand over your turn, make it a repeat (or partial repeat) of the previous one, and stop; if not, repeat and then add something different. It also has a topic-management function: by choosing what part of an utterance to repeat, a participant may help to "formulate" what aspect of the topic will be pursued, and may also display understanding of the significance of a prior utterance, of its implicatures, for example. Finally, it has an interactional function-grooming, agreeing, providing affective support. (It can also appear in confrontation, but then its use is parasitic on the affirming use: there is sarcastic agreement and affirmation of the other; see Brown 1995). Essentially "doing the same thing" as your interlocutor is a way of conveying solidarity, mutual involvement, understanding, and agreement (Brown and Levinson 1987:112-113).

Let's consider what the effect of this convention on children's language learning might be, and how it develops as a conversational skill in children's language use.

\section{Repetition in Tzeltal Adult-Child Interaction}

An important initial observation is that there is not so much dialogic repetition in adult-child interaction when the child is young, prior to age three. It is not omnipresent as it is in adult interaction, and it tends not to extend across several turns, for three reasons. (1) At first children are not able to sustain it, and (2) small children aren't treated as warranting this kind of interactional attention; indeed, they are not treated as proper conversational partners. Also, (3) generally people do not have extended things to say to small children, and vice versa. As elsewhere, children have limited conversational rights, and what is said to them involves a high proportion of directives that do not warrant repetition as a response. Children under 
the age of about three spend much of their time trotting along after the older children, silently participating in whatever is happening around them, and listening to other people's conversations, replete with repetition.

Still, there is some repetition in speech to small children from about the age of 1,0 to $1 ; 6 .{ }^{19}$ There is a certain amount of "variation set" repetition, expansion, and minimal (one-turn) dialogic repetition in obligatory contexts (e.g., answering questions). All of this is structurally revealing. It offers the opportunity for the child to isolate the salient content morpheme - often the verb root-by looking at what stays constant when other parts change.

Example (2) illustrates repetition of the variation set kind, where the adult rephrases her utterance several times (underlined in the transcript), trying to get the child's cooperation:

(2) [ $X^{\prime}$ an is 2;1, at the one-word stage; Con is her mother, Can (her elder brother) is 4]

Con: ban ak'ben chenek', lum ta moche.

X'an: ej.

Con: li' ayi.

Can: $\quad$ la' $^{\prime} \mathrm{me}^{\prime} \mathrm{ek}^{\prime} \mathrm{tz}$ 'in.

Con: ja' ini. tzaka, ban ak'a lum ta moche.

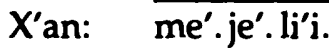

Con: li'i.li'i. ja'ich'enek' li' ayi, ba ak'a ta moch.

$X^{\prime}$ an: ejj.
'Go put the beans for me over there in the basket.'

'Eh.'

'Here they are.'

'Come on then.'

'(They)'re here. Take (them), go put (them) there in the basket.' 'Mother. Heh. Here.' [pointing] 'Here. Here.' [pointing] 'It's these beans here (they) are, go put (them) in the basket.' 'Put (them) there.' [pointing] 'Eh.' [she complies]

Here the mother rephrases her request (to put the beans in the basket) three times, putting forth different versions of the request till the child responds.

Example (3) illustrates Tzeltal expansions by the caregiver (here dotted underlining marks the child's utterance that is subsequently expanded by the mother's (underlined) utterance(s)):

(3) [Con is the mother, $X^{\prime}$ an is a girl of 2;1]

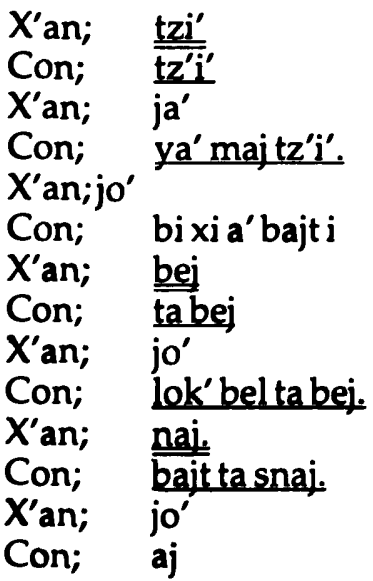

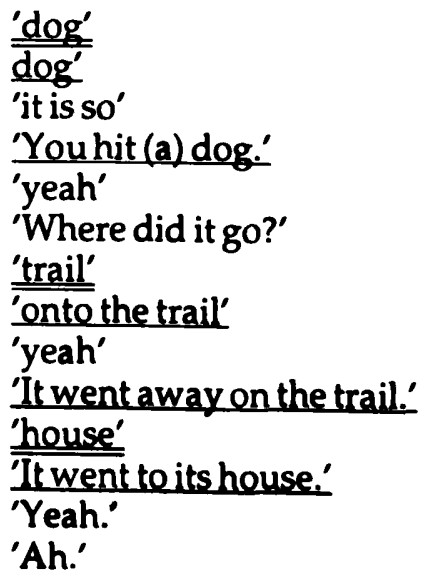

'Ah.' 


$\begin{array}{ll}\text { X'an; } & \text { najxi } \\ \text { Con; } & \text { bajtta snaj. } \\ X^{\prime} \text { an; } & \text { jae? } \\ \text { Con; } & \text { bajtix ta sna itz'i'i } \\ X^{\prime} \text { an; } & \text { ejjae? } \\ \text { Con; } & \text { bajtix ta snaj. } \\ X^{\prime} a n ; & \text { bei. } \\ \text { Con; } & \text { bajt ta bej } \\ X^{\prime} a n ; & \text { jo'.aj. }\end{array}$

'house, he/she said'
'It went to its house.'
'What?'
'The dog has gone to its house.'
'Eh, what?'
'It's gone to its house.'
'trail'
'Itwent on the trail.'
'Yeah.'

In this sequence the mother Con is interpreting the significance of the child's utterance in light of mutually known prior events, "glossing" in Scollon's (1982) terms. In doing so the mother is actually drawing out the child, a relatively infrequent occurrence in my data. More frequent is an adult 'translation' of a child's utterance to a third party who hasn't understood, as in (4):

(4) [Lus is 2;0, Mlu is her aunt, $\mathrm{PB}$ is the investigator ]

[Lus is gesturing with her lolly, telling me what happened:]

$\begin{array}{lll}\text { Lus; } & \text { bajt. xan yak'. tz'i'. } & \text { 'Gone. It-gave. Dog.' } \\ \text { PB; } & \text { binti? } & \text { 'What?' } \\ \text { Lus; } & \text { lutbel tz'i'. } & \text { '(The)dog carried it away [her } \\ \text { Mlu; } & \text { ja' laj la slut bel tz'i' te paletae. } & \begin{array}{l}\text { lolly].' } \\ \text { 'She's saying the dog carried her }\end{array} \\ \text { PB; } & \text { a ja' la slut te tz'i'e. } & \text { lolly away.' }\end{array}$

Also frequent to young children are prompting utterances attempting to get the child to repeat what was just said, often by a caregiver and older child attempting to draw the younger one into fantasy play, as in (5) (here the imitation model is double-underlined, the imitation underlined):

(5) [Xaw's elder brother Mat $(6 ; 2)$ has been talking into coke bottle, pretending to talk like the loudspeaker announcements made daily from the school, and Mo and he are trying to get Xaw $(3 ; 9)$ to do it]:
Mo; k'opojan i. tatiketikxati.
Mat: ma ba ya' lut!
jich ini.
jich nax ya' k'opon ini.
Mo; ja'extatiketik, ay moch.
aysapobilkaipexati.
Xaw: sapobilkaipe ay sapobil
'Talk. "Menfolk," you say.'
'Don't wedge it!' [the coke bottle, in her mouth]
'Like this.' [showing her] 'Just talk (into it) like this.' 'Just like that.'
"You menfolk, there are baskets (tobuy) there are coffee-washing (baskets) (for sale)." yousay. 'Coffee-washing There are wash-
ing(baskets)'

The child's repetition of the prompting model is often inaccurate, as in (5); in these play contexts exact repetition is not expected, and any utterance entering into the spirit of the play as modeled by the first speaker is accepted. 
Repetition that corresponds to dialogic repetition in adult speech-exact repetition, maintaining the syntactic frame, used to affirm the prior utterance-also appears in speech to children at this early age, often expanded to take a grammatically correct form (e.g., by adding the obligatory aspect marker and person-marking prefix that small children tend to omit). This kind of repetition is particularly reliably produced by caregivers in response to child utterances as confirmation checks of a child's expressed desires and intentions, as in Examples (6) and (7):

(6) [Lus is almost 2;6, talking to her mother]:

Lus; $\quad$ k-ichia'ini

Mo; ya'w-ich' ini.

(7) [ $X^{\prime}$ an is 2;2, talking to her father]:

$X^{\prime}$ an: t'uxajk'u'.

Fa: yaxt'uxajsk'ú.

$X^{\prime}$ an: jo'. $^{\prime}$.

Fa: $\quad k^{\prime}$ iybe me ta k'al i me sk'u' alale.

X'an: jo. yajwojxi.

Fa: ya woj.

$X^{\prime}$ an: $\mathrm{jo}^{\prime}$.
I Iget this one.' [a request to be

given some corn gruel]

'Youget this one.'

'Shirt fell off [from clothesline].' 'Her shirt fell off.'

'Huh.'

'Spread it out to dry in the sun, the child's shirt.'

'Huh. I'll toast it, he/she says. ${ }^{20}$ 'You'll toast it.'

'Huh.'

Note that the parent's production of the 1st/2nd person verb paradigm shift (ya ' $w$-ich' ini, matched to Lus's $k$-ich' $j a$ ' ini' in [6]), provides a nearminimal-pair of the sort required by the child to isolate -ich' as the relevant root, with the ' $w$-and $k$-alternation indicating deictic switches of person.

Tzeltal children show evidence of being attuned to this characteristic of conversational style very soon after they begin to speak. At the one- and two-word stage they already appropriately answer questions and suppositions with the repeated word, and they already seem to be able to pick out the semantically relevant piece to repeat as a response. For example $X^{\prime}$ an in (8) knows that she has to answer yes or no questions with a repeat of the queried item, although, since she is at the one-word stage and still produces mainly isolated verb roots, she strips the verb root of its affix and repeats it alone:

(8) [ $X^{\prime}$ an is 2;2, talking to her father]

Fa; ba' ay tz'i boj nuk'e?

$X^{\prime}$ an; li' ay i.

Fa; we'ixbala'wu'un?

$X ' a n ; w e^{\prime}$

Fa: $\quad$ we', $^{\prime}$

$X^{\prime}$ an: jo'. li' ayi.
And $X a w$, in $(9)$ knows she should repeat assessments
'Where is "cutneck"?' [X'an's favorite chicken]

'Here he is.'

'Have you fed him?' [lit: has he

eaten by means of you?]

'Eat(en).'

'Eat(en)'

'Yeah. Here he is.' 
(9) [Xaw is 2;9, talking to the investigator]:

PB; yak. luben ta we'elil.

Xaw; luben.
'Yes, he's tired from eating.'

[toy man]

(He's) tired.'

It is noteworthy that $X^{\prime}$ an and $X a w$ do not just repeat the stressed final word in these examples, but choose the semantically appropriate one to repeat, regardless of stress (which is utterance-final). That is, they have learned that affirmation must be linked to the semantics of what they are affirming; it's not just equivalent to "yes" or "uhuh."

Children at this early age seem already attuned to the fact that the form of affirmation should reflect not just the semantics but the form of the utterance being affirmed. Not all affirmations are equivalent. For example, in (10), a repeat of the prior proposition in order to affirm it needs to repeat, minimally, the ja', as $X^{\prime}$ an does:

(10) [ $X^{\prime}$ an is 2;1, Con is her mother]

Con: mach'a junuki la sti'ati?

$X^{\prime}$ an: $\quad \stackrel{\text { ja' ipoch' nuk' i? }}{\text { ja'. }}$

'Which one [if the little chickens] bit you? It was'peeled-neck'? 'Itwas.'

If $X^{\prime}$ an had repeated poch'nuk'-her name for the chicken who bit her-it would not convey the same affirmation of the prior utterance's proposition, nor would the Tzeltal word yak, meaning 'yes', which has quite limited applicability as an affirmation indicator. Answering yak 'yes' to the question in (10) would be completely inappropriate, and subject to correction, though yak is, for example, appropriate as an answer to questions about personal desires, for example, about whether one wants something to eat (as we will see in a moment). The point is that Tzeltal has no general-purpose assenter. Therefore, in (10), if you want to affirm just 'peeled-neck' that's what you would repeat; choosing the $j a$ ' assents to the whole prior utterance (that it was 'peeled-neck' who bit her). These distinctions are already partially mastered by children at the one- to two-word stage.

Conversational repeating in children's language development begins with question-answering repeats like the ones in (8) and (10). In answering a question, if a child says the equivalent of "yes" or " $\mathrm{hm}$ " instead of repeating, her utterance may be subject to overt correction or rephrasing in the interlocutors' response, as in (11):

(11) [ $X^{\prime}$ an is 2;2]

Con: ayxch'en eki a'muxuk'i.

X'an: jo.

Fa: ayxat.

X'an: ay jo'.
'Your bellybutton ithasa cave.' [teasing]

'Hm.'

'It has, you say' [correction prompt] 'Ithas. Hm.' 
There may also be explicit instruction when "yes" is required rather than "huh" or a repeat, for example, in response to a question about one's personal desires:

(12) [ $X^{\prime}$ an is 2;2]

Fa: we'bal a'wu'un?

$X^{\prime}$ an: $\quad$ we'.

Fa: $\quad$ jal tz'i ja'at ek' ya' bal a'we' waj ek?

X'an: jo'.

Fa: yakxat.

$X ' a n:$ yak.

Fa: jae?

$\mathrm{X}^{\prime}$ an: yak.

Fa: yak.

'Has it [a chicken] eaten by means of you?'

'Eat(en).'

'As for you, do you want to eat too?'

'Huh.'

$\frac{\text { 'Yes, you say.' }}{\frac{\text { 'Yes.' }}{\text { 'What?' }}}$

'Yes.'

'Yes.'

In (12), father's first yak is in the context of a prompt for $X^{\prime}$ 'an to say yak rather than just $j 0^{\prime}$; his second yak is a repeat of her yak, affirming that that's what she should say.

Repeats as affirmative answers to questions soon extend to repeating assessments (as in (8) above). By age 2,0 or so, Tzeltal children are using repetition in a number of culturally specific appropriate ways, interactively, to answer questions and affirm communicative intent. They can carry this out over extended turns, as example (13) from a conversation concerning the alleged misdeeds of the local bogeyman or "scarecrow" illustrates:

(13) [X'an is 2;1, her ElBr Can is 4]

L marks where obligatory person-marking morphemes-mostly still missing for both these children-should be; dotted underlining, as above, marks the utterance to be repeated and underlining marks the repeats]

Can: la laj wan_tzakat ta ajk'ot xutax.

X'an: $\underline{\text { la. }}$

Can: $\quad$ bi $^{\prime}$ yutat i?

$X^{\prime}$ an: la_k'ech'be_nuk' alal.

Can: la_k'okbe_nuk' alal.

$X^{\prime}$ an: jo'.

Can: sokatek.

X'an: sok._baon ek'.

Can: $\quad$ la_pojbet ch'um ek, la_pojbet ch'um.

X'an: la.

Can: sokjelolek.

$X$ 'an: sok.

Can: _lot ek'i.

X'an: boiben k'abxutax.

Can: la bojbet k'abxutax.

X'an: jo'.

Can: aj. la pojbet bel trek.
'Scarecrow grabbed you to dance with perhaps?' 'He did.'

'What did he do to you?'

'He squeezed (my) doll's neck.'

'He broke off (your) doll's neck.'

'Huh.'

'Plus you, too.' [i.e., yours too]

'Plus. I go too.'

'(He) stole squash from you, too.

(he) stole squash from you.'

'(He) did.'

'Plus from (my) namesake.'

'Plus (him).'

'(My) lie, too.' [i.e., I'm lying]

'Scarecrow cut me (my) hand.'

'Scarecrew cut you (your) hand.

'Huh.'

'(He) stole yourskirt from you.' 
X'an: la.

Can: aj.

X'an: la.

Can: $\quad$ la pojbet xan mulino.

X'an:

Can: sokmatz'.

$X^{\prime}$ an: sok.

Can: aj. la yuch'.

X'an: la.
'(He) did.'

'Ah.'

'(He) did.'

'(He) stole a corngrinder from you.' '(He)did.'

'Pluscorngruel.'

'Plus.'

'(He)drank (it).'

'(He) did!'

As for interactional conversational support (ratifying without commenting on a prior turn), Tzeltal children start with a simple grunt (ho' or hm). Dialogic repetition increases with age and vocabulary, although it is notable that children do not repeat what is syntactically beyond them. ${ }^{21}$ By age $3 ; 6$ or 4 children are able to play-act adult-style interactions, including their repetitions, and are able to engage in such conversations as the prime speaker or respondant themselves, as illustrated in (14). Here the children's repeats include variations in person, deixis, evidentiality, and mood (marked in boldface) indicating considerable mastery of the permissible variations of repeats:

(14) [Lus is 3;4, Nik is 3;11; they are talking about the pretend tortillas-actually leaves-that they are stacking in a small gourd]

(intonation rise trailing off is marked - $\wedge$ marks abrupt high pitch)

Nik; j’ajk' me nojixtal ku'un

Lus; ajk' nojixtal ek e'i ku'un

Nik; aj. ajk'uki-

Lus; Ajo'.ajk' nojix tal ku'ntik-

Nik; $\wedge_{j o}$ -
'In a moment mine got filled up.'

'In a moment mine got filled up too.'

'Ah. In sort of a moment.'

'Yeah. In a moment ours got filled up.'

'Yeah.'

Although children mostly do not engage in such conversations with adults before the age when they are sent off on errands, even before then they have the rudiments. By at least age 4 or 5 they start being sent on errands (to buy something, carry a message, or take something to another household), and can conduct an appropriately repetitive conversation with adults, both when running the errand and when reporting the gossip on their return home.

This competence is interesting in light of a general presumption in much of the child language literature that children universally start out from the same base, as it were (provided with the same innate equipment, and the same universal principles for assessing the input and for interactional organization), that they develop universal features first, and only gradually develop the idiosyncracies and style of their own language. Others (for example, Bowerman 1996; Bowerman and Choi in press; Slobin 1990), have emphasized how early a language-specific semantic flavor appears in child speech, and my observations of Tzeltal children's turn-taking using repeats are in accord with this emphasis, but in this case for a pragmatic rather 
than semantic flavor. One might expect children to start with the default Sacks et al. (1974) turn-taking rules, and only later acquire a language-specific style. Yet the Tzeltal two-year-old answering questions already sounds conversationally "native."

\section{Repetition, Verb Learning, and Interaction}

What then is the contribution of repetition to the child's task of learning Tzeltal? Because small children are not full interlocutors, and have restricted interactional rights, they are not by and large deemed worthy of the interactional attention that adults receive as a matter of course. Nonetheless, whether or not small children are the focus of interactional attention from adults, the characteristics of adult conversational style, with its systematic two-turn verb-paradigm repetitions, has the result of exposing the structure of the language, especially that of verbs, in a way that perhaps makes up for what (at least by western middle-class standards) seems like interactional neglect: not talking to children early, not having much in the way of baby talk, and not accommodating very much to children's early communicative efforts. I propose that small children's exposure to these very repetitive interchanges (even when, as usually, they are not the ones being addressed) may well alert them to the paradigmatic switches of cross-referencing affixes, deictic pronouns, and so on, which are all that differ across turns so much of the time. I suggest that it is this repetition with small variations, and the cumulative verb-stripping until nothing is left but the root, that helps children in parsing the speech stream, identifying the crucial verb roots, and learning the person-marking affixes. It amounts to a systematic exposure to paradigmatic contrasts of a crucial sort, and perhaps partly accounts for the early predominence of verbs in Tzeltal children's speech, since both variation sets and dialogic repetition have the effect of highlighting the verb root as a Figure against a shifting Ground of affixes, as Küntay and Slobin (1996) have phrased it for the analogous Turkish phenomenon. Tzeltal nouns, having much less complex morphology than verbs, and being less likely to be subject to dialogic repetition, are not particularly favored by this conversational practice.

Of course there are other properties of Tzeltal speech that probably play a role in the early appearance of verbs as well as nouns in children's language production; one important factor is the prevalence of nominal ellipsis (Brown 1998b). Given that verbs are often all that one overtly has in a Tzeltal utterance, it is important for the child to get some control of them early on in order to be able to say much of anything. But in isolating the verb roots and producing them at the one-word stage, Tzeltal children behave as if they are following a novel Operating Principle, something like: "Pay attention to what remains constant across repeated versions of an utterance, even if it is utterance-internal and prosodically unprominent." It seems reasonable to hypothesize that dialogic repetition in Tzeltal provides a form of input, available in this speech community but by no means everywhere, which can prompt its own culture-specific Operating Principle to which children orient when beginning to process speech. 
In addition to revealing the structural properties of the language, allowing roots to be isolated from affixes, dialogic repetition in the speech children are exposed to has pragmatic import, since it-like any practice designed to display agreement-undoubtedly is instrumental in socializing social alignment and displays of attention and involvement. As such, it plays an important role in socializing the collaborative style of social interaction adults favor in this community, a style that children are able to perform by about age four. This Tzeltal case illustrates how there may be a direct link between a language socialization practice and the language acquisition process. ${ }^{22}$ The character of talk to and around small children provides a socialization mechanism that both lays bare the linguistic structure of utterances and foregrounds the collaborative nature of Tzeltal interactional style. Despite the fact that their participant role up to about age two is more often that of a bystander than an interlocutor, Tzeltal children are exposed to languagelab-like paradigms in the conversational speech around them. They are also encouraged to share meanings across turns by sharing the very form of words when they respond.

What I have argued here is that aspects of conversational style in a culture or subculture can affect the nature of children's exposure to language in ways that at least partly help to solve the mysteries of how children can acquire a linguistic system so fast, from such allegedly minimal input. Despite the relatively passive beginnings of Tzeltal language acquisition, given the highly repetitious nature of much Tzeltal verbal interaction children rapidly master the rudiments both of Tzeltal verb morphology and of that interactional style. In short the input is not as "degenerate" or unhelpful as some researchers have suggested.

Maybe this is not so surprising after all. The "father" of modern first-language acquisition research, Roger Brown, observed (1968:288), "The changes produced in sentences as they move between persons in discourse may be the richest data for the discovery of grammar." In the Tzeltal case, conversational organization makes this an even more salient and systematic source of cues for the discovery of structural patterns in the language.

\section{Notes}

Acknowledgments. This is a revised version of part of a paper initially given as a plenary talk at the 5th International Pragmatics Association conference in Mexico City, July 1996. It was also aired at the 1997 Meetings of the American Anthropological Association, and at a seminar during the 1998 CLIC conference at UCLA. I am very grateful to E. Schegloff for detailed critical comments on the issues raised herein.

1 . Dissenting voices to this picture have come mainly from anthropologists. Speech communities where there is reported to be minimal talk to prelinguistic infants, and a minimal motherese register, include a black working-class community in North Carolina (Heath 1983), the Samoans (Ochs 1982, 1988), the Javanese (SmithHefner 1988), and the New Guinea Kaluli (Schieffelin 1979, 1990). It has also recently been pointed out that the existence of a baby-talk register does not necessarily mean a simpler task for the child; Crago and Allen (1997) show that, even though some 30 percent of input to Inuktitut infants is in baby-talk words, most of this input is morphologically complex. 
2. See Brown 1996 for details on the nature of talk to Tzeltal infants, de León 1999 for Tzotzil, and Pye 1986 for similar observations in a K'iche' Mayan community. The language socialization literature provides evidence that Mayan societies are by no means unique in this respect; there is only a minimal simplified register of childdirected speech in a number of other languages and cultures (see Ochs and Schieffelin 1995 for a review).

3. Maratsos (1998) points out that these should properly be called "prospective verbs," since it is not clear that a child at the one-word stage has a category distinction between nouns and verbs. In Tzeltal these are roots which for adults are verbs, and which the child seems to use to label actions.

4. See de León 1999 for Tzotzil, Pye 1992 for K'iche'. It also appears to be the case in Korean and Chinese (Choi 1997; Tardif 1996), although in the studies of these Asian languages reporting that children also produce many early verbs, the input (from educated, middle-class parents) is more like that in the heavily studied European languages.

5. Recent studies of babies have produced abundant evidence that very early (between at least 6 to 9 months of age) they become sensitive to the phonological structure-including consonants and vowels, intonation and stress patterns-of their language. A summary of this research can be found in van de Weijer 1998.

6. The recorded database consists of over 600 hours of tape-recorded or videotaped natural interaction, collected every four to six weeks mostly in the children's own homes, with caregivers and siblings and/or cousins as interlocutors. This child database is supplemented by another corpus of adult Tzeltal natural conversation (mostly audio but some video) in a wide variety of contexts, collected over the years since 1971.

7. There is some variation in this in different families; first babies especially may receive more interactional attention. The same picture of minimal interaction with infants has been reported for other Mayan societies (Gaskins 1996; Pye 1986), as well as for other societies around the world (see, for example, Heath 1983; Ochs 1988; Schieffelin 1990; Ward 1971).

8. These involve noncommunicative signs that something is about to happen (like clouds betoken rain), to which the mother contingently responds by attending to the perceived need of the infant (Gaskins 1996; Rogoff 1990).

9. Extrapolating from the many hours I have spent observing in five different Tzeltal households, I would estimate a maximum of 20 to 30 utterances per day during the child's first year. I have, for example, witnessed many times a mother silently bathing her baby, or nursing it while holding a conversation with someone else, or working, or sleeping. In this first year, the baby is more like an object, or like a part of the mother's body, than like a separate individual with whom one interacts.

10. This compares with a total of perhaps 20 to 30 times that much in a middleclass family in Western societies. See, for example, the recent study on input to a Dutch infant of six to nine months (van der Weijer 1998).

11. A whole session on Mayan "dialogic repetition" was part of the CAIL sessions at the 1996 Annual Meeting of the American Anthropological Association in San Francisco.

12. Repetition in child discourse also has a large literature, coming originally from the Piagetian tradition, especially with respect to small children's putative propensity for imitation; see for example Slobin 1968, Bloom 1991, chapters 12 and 13, Camaioni 1979, Snow 1983. In adult speech the role of repetition in creating various kinds of coherence in discourse has been much discussed; see, e.g., Johnstone 1994, Keenan 1977, Tannen 1987a, 1987b, 1989. See, e.g., Schegloff 1996b, Goodwin and Goodwin 1987, for functions of repetition in the sequential organization of talk. 
13. Küntay and Slobin (1996) offer an English example: a father trying to prompt the memory of a child of 2;3 says: "Who did we see when we went out shopping today? Who did we see? Who did we see in the store? Who did we see today? When we went out shopping, who did we see?"

14. The Tzeltal transcription is roughly phonemic, and uses a practical orthography prescribed for Mayan languages: $j$ stands for [ $h$ ], $x$ for [sh], ch for [ch], and ' indicates a glottal stop or glottalization of the prior consonant. Additional transcription symbols include: $\wedge$ marking abrupt shift to high pitch, - -high trailing off intonation, : lengthening of the preceding phoneme, (.) a micropause, and = hatching.

15 . Tzeltal is a mildly polysynthetic language, with rich and highly productive derivational morphology for changing the valency or class of roots. Verb stems have obligatory aspect particles and consistent (nonsplit) ergative/absolutive personmarking affixes, while noun stems may have ergative possessive marking (as a prefix), absolutive suffixes (when being used as a predicate, as in antz-on, 'I am a woman', or plural marking (as a suffix).

16. See Brown 1979 (chapter 4), 1990, 1995, 1996, for further analysis and examples of this kind of repetition in Tzeltal conversation.

17. I owe this observation, with thanks, to an anonymous reviewer.

18. At least insofar as we can infer from their overt behavior: children at public events run freely in and out of the event space, and display other signs of nonattention. This is in marked contrast with their behavior when visiting at others' homes; even small children are expected to sit quietly throughout adult visiting conversations.

19. Children's ages are given in years and months (e.g., 2;6 means 2 years; 6 months of age).

20. The verb $x i$ 'he or she says' can also be read as an imperative 'say' (though it can not be explicitly marked as imperative), or as the generic 'one says'. However, it is not a prompt here; this child's routine use of 'he or she says' reflects the frequency of caregiver prompts to her at this stage.

21. For example, a number of the children in my sample tend to omit the obligatory intransitive aspectual prefix $x$ - even in repeats immediately following the correct model, for several years (Brown 1997).

22. For arguments proposing this kind of link, see Schieffelin and Ochs 1986, Ochs and Schieffelin 1995.

\section{References Cited}

Bloom, Lois

1991 Language Development from Two to Three. Chapters 12 and 13. Cambridge: Cambridge University Press.

Bowerman, Melissa

1996 The Origins of Children's Spatial Semantic Categories: Cognitive vs. Linguistic Determinants. In Rethinking Linguistic Relativity. J. J. Gumperz and S.

C. Levinson, eds. Pp. 145-176. Cambridge: Cambridge University Press.

Bowerman, Melissa, and Soonja Choi

In press Shaping Meanings for Language: Universal and Language Specific in the Acquisition of Spatial Semantic Categories. In Language Acquisition and Conceptual Development. M. Bowerman and S. C. Levinson, eds. Cambridge: Cambridge University Press.

Brody, Jill

1986 Repetition as a Rhetorical and Conversational Device in Tojolabal (Mayan). IJAL 52(3):255-274. 
1994 Multiple Repetitions in Tojolobal Conversation. In Repetition in Discourse: Interdisciplinary Perspectives, 2. Barbara Johnstone, ed. Pp 3-14. New York: Ablex.

1996 Dialogic Parallelism in Tojolab'al Maya. Paper presented at the CAIL sessions, Annual Meeting of the American Anthropological Association, San Francisco.

Brown, Penelope

1979 Language, Interaction, and Sex Roles in a Mayan Community. Ph.D dissertation, University of California, Berkeley.

1990 Gender, Politeness, and Confrontation in Tenejapa. Discourse Processes 13(1):123-141.

1995 Politeness Strategies and the Attribution of Intentions: The Case of Tzeltal Irony. In Social Intelligence and Interaction. E. Goody, ed. Pp. 153-174. Cambridge: Cambridge University Press.

1996 The Conversational Context for Language Acquisition: A Tzeltal (Mayan) Case Study. Plenary lecture delivered at the 5th International Pragmatics Association conference, Mexico City.

1997 Isolating the CVC Root in Tzeltal Mayan: A Study of Children's First Verbs. In Papers from the 28th Child Language Research Forum. E. V. Clark, ed. Pp. 41-52. Stanford: CSLI.

1998a Children's First Verbs in Tzeltal: Evidence for an Early Verb Category. Linguistics 36(4):713-753.

1998b Verb Specificity and Argument Realization in Tzeltal Child Language. Paper delivered at the Workshop on "Cross-Linguistic Perspectives on Argument Structure: Implications for Learnability," Max Planck Institute for Psycholinguistics, Nijmegen, June 1998. To appear in a volume edited by M. Bowerman and P. Brown, in prep.

Brown, Penelope, and Stephen Levinson

1987 Politeness: Some Universals in Language Usage. Cambridge: Cambridge University Press.

Brown, Roger W.

1968 The Development of Wh Questions in Child Speech. Journal of Verbal Learning and Verbal Behaviour 7:279-290.

Brown, Roger W., and Ursula Bellugi

1964 Three Processes in the Child's Acquisition of Syntax. In New Directions in the Study of Language. E. H. Lenneberg, ed. Pp. 131-161. Cambridge: MIT Press.

Camaioni, Luigia

1979 Child-Adult and Child-Child Conversations: An Interactional Approach.

In Developmental Pragmatics. Elinor Ochs and Bambi Schieffelin, eds. Pp. 325-337. New York: Academic Press.

Choi, Soonja

1997 Language-Specific Input and Early Semantic Development: Evidence from Children Learning Korean. In The Crosslinguistic Study of Language Acquisition, 5. D. I. Slobin, ed. Pp. 41-133. Mahway, NJ: Erlbaum.

\section{Clark, Eve}

1993 The Lexicon in Acquisition. Cambridge: Cambridge University Press.

Crago, Martha B., and Shanley E. M. Allen

1997 Linguistic and Cultural Aspects of Simplicity and Complexity in Inuktitut Child Directed Speech. Proceedings of the 21st Boston University Conference 
on Child Language Development, 1. Pp. 91-102. Somerville, MA: Cascadilla Press.

Cruttenden, Alan

1994 Phonetic and Prosodic Aspects of Baby Talk. In Input and Interaction in

Language Acquisition. Clare Gallaway and Brian Richards, eds. Pp. 135-152.

Cambridge: Cambridge University Press.

de León, Lourdes

1999 Early Verb Roots in Tzotzil (Mayan) Acquisition: The Role of Caregiver Speech and Discourse Patterns. In Cognition and Function in Language. Barbara A. Fox, Daniel Jurafsky, and Laura Michaelis, eds. Pp. 99-119. Stanford: CSLI.

Demuth, Katherine

1986 Prompting Routines in the Language Socialization of Basotho Children. In Language Socialization across Cultures. B. Schieffelin and E. Ochs, eds. Pp. 51-79. Cambridge: Cambridge University Press.

Eisenberg, Ann R.

1986 Teasing: Verbal Play in Two Mexicano Homes. In Language Socialization across Cultures. B. Schieffelin and E. Ochs, eds. Pp. 182-198. Cambridge: Cambridge University Press.

Fought, John

1985 Cyclical Patterns in Chorti (Mayan) Literature. In Supplement to the Handbook of Middle American Indians, 3. Munro S. Edmonson, ed. Pp. 147-170. Austin: University of Texas Press.

Gaskins, Suzanne

1996 How Mayan Parental Theories Come into Play. In Parents' Cultural Belief Systems: Their Origins, Expressions, and Consequences. Sara Harkness and Charles M. Super, eds. Pp. 345-363. New York: Guilford Press.

Gentner, Dedre

1978 On Relational Meaning: The Acquistion of Verb Meanings. Child Development 49:988-990.

1982 Why Nouns Are Learned before Verbs: Linguistic Relativity vs. Natural Partitioning. In Language Development, 2: Language, Thought and Culture. S. A. Kuczaj II, ed. Pp. 301-334. Hillsdale, NJ: Erlbaum.

Gleitman, Lila

1990 The Structural Source of Verb Meanings. Language Acquisition 1:3-55.

Goodwin, Charles, and Marjorie Goodwin

1987 Concurrent Operations on Talk: Notes on the Interactive Organization of Assessments. Papers in Pragmatics 1(1):1-54.

Gopnik, Alison

1981 Development of Non-nominal Expressions in 1-2-Year-Olds: Why the First Words Aren't about Things. In Child Language: An International Perspective. Philip S. Dale and David Ingram, eds. Pp. 93-104. Baltimore: University Park Press.

Hanks, William

1989 Elements of Maya Style. In Word and Image in Maya Culture: Explorations in Language, Writing and Representation. W. F. Hanks and Don S. Rice, eds. Pp. 92-111. Salt Lake City: University of Utah Press.

Heath, Shirley Brice

1983 Ways with Words. Cambridge: Cambridge University Press. 


\section{Hofling, Charles}

1993 Marking Space and Time in Itzaj Maya Narrative. Journal of Linguistic Anthropology 3(2):164-184.

1996 Dialogic Repetition in Mayan Discourse. Paper presented at the CAIL sessions, Annual Meeting of the American Anthropological Association, San Francisco.

Johnstone, Barbara, ed.

1994 Repetition in Discourse: Interdisciplinary Perspectives, 1 and 2. Norwood, New Jersey: Ablex.

Keenan (Ochs), Elinor

1977 Making It Last: Uses of Repetition in Children's Discourse. In Child Discourse. S. Ervin-Tripp and C. Mitchell-Kernan, eds. Pp. 125-138. New York: Academic Press.

Küntay, Aylin, and Dan I. Slobin

1996 Listening to a Turkish Mother: Some Puzzles for Acquisition. In Social Interaction, Social Context, and Language: Essays in Honor of Susan Ervin-Tripp. D. I. Slobin, J. Gerhardt, A. Kyratzis, and J. Guo, eds. Pp. 265-286. Hillsdale, NJ: Erlbaum.

Maratsos, Michael

1998 Commentary: Relations of Lexical Specificity to General Categories. Linguistics 36(4):831-846.

Markman, E. M.

1994 Constraints on Word Meaning in Early Language Acquisition. In The Acquisition of the Lexicon. Lila Gleitman and Barbara Landau, eds. Pp. 199-227. Cambridge: MIT/Elsevier.

Martin, Laura

1994 Rhetorical Elaboration and Discourse Structure in Mocho. Journal of Linguistic Anthropology 4(2):131-152.

In press Parallelism and the Spontaneous Ritualization of Ordinary Talk: Three Mocho Friends Discuss a Volcano. In Translating Native Latin American Verbal Art: Ethnopoetics and Ethnography of Speaking. Kay Sammons and Joel Sherzer, eds. Washington: Smithsonian Institution Press.

Norman, William N.

1980 Grammatical Parallelism in Quiche Ritual Language. Proceedings of the

6th Annual Meeting of the Berkeley Linguistic Society. Pp. 387-399. Berkeley:

University of California Press.

Ochs, Elinor

1982 Talking to Children in Western Samoa. Language in Society 11:77-104.

1984 Clarification and Culture. In Georgetown University Round Table on Language and Linguistics. D. Schiffrin, ed. Pp. 325-341. Washington: Georgetown University Press.

1988 Culture and Language Development. Cambridge: Cambridge University Press.

1991 Misunderstanding Children. In "Miscommunication" and Problematic Talk. N. Coupland, H. Giles, and J. M. Wiemann, eds. Pp. 44-60. Newberry Park: Sage.

Ochs, Elinor, and Bambi Schieffelin.

1995 The Impact of Language Socialization on Grammatical Development. In The Handbook of Child Language. Paul Fletcher and Brian MacWhinney, eds. Pp. 73-94. Oxford: Blackwell. 
Pine, Julian

1994 The Language of Primary Caregivers. In Input and Interaction in Language Acquisition. Clare Gallaway and Brian Richards, eds. Pp. 15-37. Cambridge: Cambridge University Press.

Pye, Clifford

1986 Quiche' Mayan Speech to Children. Journal of Child Language 13:85-100.

1992 The Acquisition of K'iche' Maya. In The Cross-Linguistic Study of Language Acquisition. D. I. Slobin, ed. Pp. 222-308. Hillsdale, NJ: Erlbaum.

Rogoff, Barbara

1990 Apprenticeship in Thinking: Cognitive Development in Social Context. New York: Oxford University Press.

Sacks, Harvey, Emanuel A. Schegloff, and Gail Jefferson

1974 A Simplest Systematics for the Organization of Turn-Taking for Conversation. Language 50:696-735.

Schegloff, Emanuel A.

1981 Discourse as an Interactional Achievement: Some Uses of 'Uhhuh' and Other Things that Come between Sentences. In Analyzing Discourse: Text and Talk. D. Tannen, ed. Pp. 71-93. Georgetown University Roundtable on Languages and Linguistics. Washington, DC: Georgetown University Press.

1996a Pragmatics, Conversation, Analysis. Plenary lecture delivered at the 5th International Pragmatics Conference, Mexico City.

1996b Confirming Allusions: Toward an Empirical Account of Action. American Journal of Sociology 102(1):161-216.

Schieffelin, Bambi B.

1979 Getting It Together: An Ethnographic Perspective on the Study of the Acquisition of Communicative Competence. In Developmental Pragmatics. E. Ochs and B. B. Schieffelin, eds. Pp. 73-108. New York Academic Press.

1990 The Give and Take of Everyday Life. Cambridge: Cambridge University Press.

Schieffelin, Bambi B., and Elinor Ochs, eds.

1986 Language Socialization across Cultures. Cambridge: Cambridge University Press.

Scollon, Susanne

1982 Reality Set, Socialization, and Linguistic Convergence. Ph.D. dissertation, University of Hawaii.

Slobin, Dan I.

1968 Imitation and Grammatical Development in Children. In Contemporary Issues in Developmental Psychology. N. Endler, L. Boulter, and H. Osser, eds. Pp. 437-443. New York: Holt, Rinehart and Winston.

1985 Cross-Linguistic Evidence for the Language Making Capacity. In The Cross-Linguistic Study of Language Acquisition, 1. D. I. Slobin, ed. Pp. 1157-1256. Hillsdale, NJ: Erlbaum.

1990 The Development from Child Speaker to Native Speaker. In Cultural Psychology. J. W. Stigler, R. A. Shweder, and G. Herdt, eds. Pp.233-256. Cambridge: Cambridge University Press.

Smith-Hefner, B.

1988 The Linguistic Socialization of Javanese Children. Anthropological Linguistics 30(2):166-198. 


\section{Snow, Catherine E.}

1981 Social Interaction and Language Acquisition. In Child Language-An International Perspective. Philip S. Dale and David Ingram, eds. Pp. 195-214. Baltimore: University Park Press.

1983 Saying It Again: The Role of Expanded and Deferred Imitations in Language Acquisition. In Children's Language, 4. Keith E. Nelson, ed. Pp. 29-58. Hillsdale, NJ: Erlbaum.

1984 Parent-Child Interaction and the Development of Communicative Ability. In The Acquisition of Communicative Competence. R. L. Schiefelbusch and J. Pickar, eds. Pp. 69-107. Baltimore: University Park Press.

Snow, Catherine E., and Charles A. Ferguson

1977 Talking to Children: Language Input and Acquisition. Cambridge: Cambridge University Press.

Stolz, Christel

1996 Couplet Parallelism in Informal Speech Genres: Evidence from Yucatec Maya. Paper presented at the CAIL sessions, Annual Meeting of the American Anthropological Association, San Francisco.

Tannen, Deborah

1987a Repetition in Conversation: Toward a Poetics of Talk. Language 63(3): 574-605.

1987b Repetition in Conversation as Spontaneous Formulaicity. Text 7(3): 215-243.

1989 Talking Voices: Repetition, Dialogue, and Imagery in Conversational Discourse. Cambridge: Cambridge University Press.

Tardif, Twila

1996 Nouns Are not Always Learned before Verbs: Evidence from Mandarin Speakers' Early Vocabularies. Developmental Psychology 32(3):492-504.

Tedlock, Dennis

1983 The Forms of Mayan Verse. In The Spoken Word and the Work of Interpretation, D. Tedlock, ed. Pp. 216-232. Philadelphia: University of Pennsylvania Press.

van de Weijer, Joost

1998 Language Input for Word Discovery. Ph.D. dissertation, University of Nijmegen, The Netherlands.

Ward, $M$.

1971 Them Children: A Study in Language. New York: Holt, Rinehart and Winston.

Watson-Gegeo, Karen Ann, and David W. Gegeo

1986 Calling-Out and Repeating Routines in Kwara'ae Children's Language Socialization. In Language Socialization across Cultures. B. Schieffelin and E. Ochs, eds. Pp. 17-50. Cambridge: Cambridge University Press. 